\title{
CONFLICTOS TERRITORIALES EN MISIONES: UNA RECONSTRUCCIÓN HISTÓRICA DE LA OCUPACIÓN ESPONTÁNEA DE TIERRAS PRIVADAS A FINALES DEL SIGLO XX
}

\author{
Territorial conflicts in Misiones: A historical reconstruction of the going \\ occupation of private lands at the end of the twentieth century
}

\author{
Sebastián Ramirez* \\ https://orcid.org/0000-0002-7852-6876
}

\section{Resumen}

El propósito del artículo es reconstruir el proceso de ocupación espontánea de terrenos privados en el nordeste de la provincia de Misiones, con el objeto de identificar los factores que originaron los conflictos territoriales que tuvieron lugar en la región a finales del siglo XX. Concretamente, se busca construir una línea sociohistórica del conflicto por la tierra, haciendo foco en la relación existente entre Estado, procesos de colonización privada y transformaciones ocurridas en el agro misionero vinculadas a la actividad forestal.

$$
<\text { Conflictos territoriales }><\text { Ocupación espontánea }><\text { Misiones }>
$$

\begin{abstract}
The purpose of the article is to reconstruct the process of spontaneous occupation of private lands in the northeast of the province of Misiones, in object to identify the factors that caused the territorial conflicts that took place in the region at the end of the twentieth century. Specifically, it seeks to build a sociohistoric line of conflict over the lands, focusing on the relationship between state, private colonization processes and transformations in the agro-misionero linked to forestry.

$<$ Territorial conflicts $><$ Spontaneous occupation $><$ Misiones $>$
\end{abstract}

Recibido: 24/04/2019

Aceptado: 23/07/2019

\section{Introducción}

Hacia fines de 1970, en simultáneo con la crisis de la forestoindustria y el abandono de terrenos por parte de las empresas forestales, comenzó a gestarse en el nordeste de la provincia de Misiones un proceso de ocupación de terrenos que se generalizó durante los años noventa. Esta nueva forma de poblamiento conocida como ocupación espontánea de terrenos privados, a diferencia de la colonización oficial,

\footnotetext{
* Facultad de Humanidades y Ciencias Sociales, Universidad Nacional de Misiones. Consejo Nacional de Investigaciones Científicas y Técnicas (CONICET), Argentina. 1sr.sebastian@gmail.com
} 
Ramirez. Conflictos territoriales en Misiones: una reconstrucción histórica de la ocupación espontánea de tierras...

presentó un carácter no planificado y estuvo protagonizada por familias de pequeños productores que se asentaron en la zona. A raíz de la inversión de capital extranjero a mediado de 1990, se restableció el valor productivo de las fincas abandonadas; lo que desató un período complejo de pugna entre población rural ocupante y empresarios forestales. Recién en este momento el Estado intervino en el conflicto, asumiendo un rol arbitral entre las partes involucradas. Mientras los ocupantes exigían la mediación estatal para regularizar las parcelas que ocupaban desde hacía más de una década con producción tabacalera, los propietarios de las compañías forestales reclamaban la devolución de los terrenos que, en muchos casos, se encontraban habitados por exempleados despedidos luego del abandono de las mismas.

La hipotesis general que orienta la investigación indica que los conflictos desatados por el fenómeno de ocupación espontánea de terrenos privados, en el nordeste de la provincia de Misiones, son la resultante de una serie de fenómenos históricos contradictorios que se sucedieron entre 1920 -momento inicial de la fundación de colonias en el norte- y 1995, cuando las transformaciones en la estructura social agraria, producidas por el desarrollo foresto-industrial, profundizaron las desigualdades socioeconómicas en la región. En este contexto, la intervención del Estado (nacional y provincial) benefició a las compañías forestales a través de diferentes mecanismos de compensación, garantizándoles el normal desempeño de sus capitales.

Para dar cuenta de estos aspectos, en primer término, se explicitarán los elementos conceptuales con los que se analizará la conflictividad territorial en el área bajo estudio. Luego, se expondrá una síntesis histórica del poblamiento de Misiones que permitirá observar los factores que originaron el agotamiento de la frontera agrícola y el proceso de ocupación espontánea de terrenos privados. Posteriormente, se realizará una cronología del conflicto por la tierra, construida a partir de una selección de testimonios obtenidos durante experiencias en campo (septiembre de 2015, noviembre de 2017 y febrero de 2019), artículos de prensa escrita, archivos documentales y bibliografía especializada. Para finalizar, se delinearán una serie de reflexiones a modo de propuesta para el abordaje de los conflictos territoriales en el nordeste de la provincia de Misiones.

\section{Marco conceptual}

\section{Lucha de clase, conflictos y Estado}

En el desarrollo del método materialista, propuesto por Karl Marx, los principios de la investigación histórica ocupan un lugar central. Uno de sus aportes más significativos a las ciencias sociales -aunque no el único-, fue su concepción de la realidad como totalidad concreta, "un todo estructurado y dialéctico en el cual los hechos puedan ser comprendidos" (Kosik, 1967). Marx (2004), concebía a lo concreto como la unidad de lo diverso, que "es concreto porque constituye la síntesis de numerosas determinaciones". Por este motivo, la simple conjunción de los hechos no logra expresar todavía la totalidad del conocimiento de la realidad. Para ello, es necesario que los mismos sean partes constitutivas de un concreto dialéctico desde donde fuera posible 
"captar toda realidad exactamente como es y a su vez como debiera ser, de acuerdo a lo que ella misma contiene en potencia” (Peña, 1958).

El pensador de Tréveris aseguró, además, que "la historia de todas las sociedades que han existido hasta nuestros días, es una historia de lucha de clases". De ahí nuestra consideración acerca de que, a) los conflictos son inherentes a todas ellas y asumen la forma de "un conjunto de relaciones sociales dialécticas que expresan diferentes tipos y grados de conflictividad" (Graciosi, 2018) y b) su desarrollo se encuentra siempre condicionado por contradicciones principales y secundarias, posibles de ser resueltas por medio de una pugna entre contrarios que inaugure un nuevo estadio, o a partir de la superación de la contradicción, mediante una destrucción dialéctica de los opuestos que instaure un nuevo modo de producción.

De esta manera, cada nueva forma productiva responde a una relación social general que estará determinada, en última instancia, por la forma que en cada caso el trabajo excedente sea extraído del productor directo. Así, a diferencia del modo de producción feudal -en donde el señor poseía la propiedad completa sobre los medios de producción, y a partir de allí, establecía una relación de servidumbre o vasallaje con el siervo-, en el sistema capitalista, el capital se presenta como una relación social que tiene lugar en los procesos de producción de una formación histórico-social específica ${ }^{1}$ a la que Marx definió con el nombre de modo de producción específicamente capitalista o "forma general, socialmente dominante del proceso de producción" (Marx, 2009a), donde a cada individuo se le asigna una parte del producto del trabajo social que le corresponde consumir, determinando con ello la organización privada del trabajo social. Bajo esta forma, los productores de mercancías no se encuentran sujetos a dependencia personal alguna (como si lo estuvieron durante el feudalismo) hallándose personificados, entiéndase objetivados, por las mercancías que producen, las cuales aparentan tener una cualidad inherente a su propia existencia para generar plusvalor durante el proceso de producción y realizarse durante el proceso de circulación de mercancías. De este movimiento concreto surge la unidad del movimiento del capital como organizador de la de vida social²; el cual garantiza su reproducción gracias a una cada vez más creciente producción de mercancías, que eleva la proporción de plusvalor del que se apropian los capitalistas, producto de una explotación también creciente de la clase obrera. Esto origina la contradicción principal en el modo de producción capitalista entre capital y trabajo.

\footnotetext{
1 En una nota al pie en el volumen III del tomo I de El Capital, Marx avanza sobre una explicación más esquemática de su idea acerca de que el capital no es una cosa sino una relación social mediada por cosas: "Un negro es un negro. Sólo bajo determinadas condiciones se convierte en esclavo. Una máquina de hilar algodón es una máquina de hilar algodón. Sólo bajo determinadas condiciones se convierte en capital. Desgajada de esas condiciones, la máquina dista tanto de ser capital como dista el oro, en sí y para sí, de ser dinero y el azúcar de ser el precio del azúcar. El capital es una relación social de producción. Es una relación histórica de producción" (Marx, 2009b).

2 Para ampliar la noción de capital como sujeto organizador de la vida social, se recomienda los desarrollos de Juan Iñigo Carrera (2013, cap. 1: Razón histórica y sujeto revolucionario. En "El capital: razón histórica, sujeto revolucionario y conciencia") y Juan Iñigo Carrera (2015: "Del capital como sujeto de la vida social enajenada a la clase obrera como sujeto Revolucionario").
} 
Ramirez. Conflictos territoriales en Misiones: una reconstrucción histórica de la ocupación espontánea de tierras...

Llegado a determinado nivel del desarrollo de las fuerzas productivas del trabajo social, esta contradicción se vuelve objetivamente irreconciliable. Se trata de "la confesión de que una sociedad se ha enredado en una irremediable contradicción consigo misma y está dividida por antagonismos irreconciliables" (Engels, 1992). Para dar solución a este antagonismo, sin acabar con las condiciones que necesita el capital para reproducirse, se precisa un poder situado en apariencia por encima de la sociedad "y llamado a mantenerlo en los límites del orden" (Engels, 1992). Ese poder, nacido de la sociedad de clases pero posicionado por encima de ella, es el Estado. En el caso que se analiza, el aparato estatal limitó su participación en el desarrollo del conflicto ocupando el lugar de mediador entre cada fracción de clase una vez que sus objetivos se expresaron incompatibles. En un extremo se ubicaban cientos de familias rurales que demandaban la regularización de las fincas que ocupaban hacia una década y, en el otro, las compañías forestales que habían resultado favorecidas, hacia 1995, por una fuerte inversión de capital extranjero que propició "la emergencia del modelo de agronegocio forestal" (Ramirez, 2017). Al alzarse como mediador, el Estado no hizo más que exponer cabalmente la naturaleza de la relación social que lo constituye como tal en el modo de producción capitalista, el de ser el vehículo de realización de la lucha de clases; pues mientras más se desarrolla la acumulación de capital, más necesita la regulación autónoma capitalista realizarse tomando la forma concreta de regulación directa por el Estado (Caligaris, 2012; Iñigo Carrera, 2000). De esta manera, la premisa de Engel acerca de que el "Estado no es, en general, más que el reflejo en forma sintética de las necesidades económicas de la clase que gobierna la producción" (Engels, 1886), es un buen punto de partir para comprender el comportamiento de éste en la conflictividad territorial del nordeste de Misiones.

\section{Acumulación de capital y estructura de clase del nordeste de Misiones}

Para el agro capitalista la tierra representa siempre un factor tan determinante como particularmente problemático. Si bien su presencia no altera la naturaleza de la explotación bajo la relación social general en la producción agrícola capitalista, sus efectos le otorgan a la dinámica entre las clases ciertas particularidades que no se encuentran en los ámbitos urbanos. En el campo, las clases están representadas por el capitalista agrario, el obrero rural y el terrateniente. Al igual que en la producción industrial, éstos "se encuentran condicionados por el movimiento concreto de las mercancías específicas que tienen a su cargo personificar: el capital, la fuerza de trabajo y la propiedad territorial" (Caligaris, 2017) respectivamente. Sin embargo, pese a que el capital agrario tampoco abandona su tendencia general, esto es, a concentrar y centralizar mayores masas de capital en menos manos, y a eliminar progresivamente a los productores más pequeños; las limitaciones del suelo, las fluctuaciones en las condiciones naturales y el carácter prolongado del proceso de producción en el agro afectan directamente la acumulación de capital en esta rama y, en consecuencia, a la contradicción establecida entre capital y trabajo.

En el nordeste de la provincia de Misiones la conflictividad se manifestó por uso indiscriminado de un bien común, en este caso la tierra, por lo que la contradicción 
principal que da origen a la lucha de clases no parece establecerse estrictamente entre capital y trabajo, sino entre el "capital y sus condiciones de reproducción". Al respecto, Galafassi (2014) manifiesta que durante las últimas décadas se observa la emergencia de luchas en donde la clase obrera no aparece bajo la forma de una "fuerza de trabajo que se autorreconoce y resiste, sino más bien como aquella capaz de denunciar la dominación/ explotación que se vivencia en el propio ámbito de las condiciones de producción y de vida, por fuera del puesto de trabajo" (Galafassi, 2014). Esto de ninguna manera niega la contradicción entre capital y trabajo, lo que por otro lado estaría poniendo en duda el desarrollo capitalista en el agro misionero. Por el contrario, expresa un mayor nivel de complejidad en la dinámica de clases, en un territorio donde el modelo de acumulación forestal organizó las relaciones productivas, sociales y políticas alrededor de la explotación de la tierra. De esta manera, capitalistas agrarios propietarios de enormes latifundios dedicados a la actividad forestal y sus derivados, enfrentaron a obreros rurales que ante el agotamiento de la frontera agrícola -en una etapa posterior a las ocupaciones-, reproducían su vida material como infantería ligera del capital; esto es, a partir de constantes desplazamientos que les permitían emplearse en tareas estacionales.

La situación cambió, sin embargo, cuando esta población se encontró asentada en las tierras que ocuparon. Fundamentalmente en aquellos casos en que las familias se dedicaron a la producción tabacalera, pues su reproducción asumió la forma de otra fracción de clase obrera, la de un productor mercantil simple; definido de esta manera por su capacidad para producir una mercancía, en este caso tabaco, que luego la vendía en el mercado. Empero, por motivos que ya hemos detallado, este productor se encontraba incapacitado para explotar fuerza de trabajo ajena e imposibilitado para detentar legítimamente las fincas sobre las que producía. Ya Marx había advertido que el acceso directo a los medios de producción puede adquirir muchas formas, algunas de las cuales pueden también coexistir históricamente con formas de explotación (Marx, 2009). No obstante, esta particularidad que presentaban los ocupantes productores de tabaco $^{3}$, dio lugar a que otras investigaciones aseguraran que se trataba de "una población con características campesina" (Baranger, 2008), lo que los ubicaba bajo la "excepcionalidad" que soslaya las condiciones de trabajo a las que son sometidos. Condiciones, cabe remarcar, propias del desarrollo capitalista en este cultivo.

\section{Misiones: De la colonización al agotamiento de la frontera agrícola}

\section{La ocupación del Territorio Nacional de Misiones}

Hacia 1880, en medio del conflicto por la región misionera ${ }^{4}$, el Estado brasileño decidió instalar asentamientos militares en el espacio enmarcado por los ríos Pepirí

\footnotetext{
3 En Ramirez, 2015, "Trabajo que se hace humo"... mostramos como los ocupantes dedicados al cultivo de tabaco son estrictamente trabajadores de las cooperativas tabacaleras, las cuales entregan todos los medios de producción necesarios para esta tarea bajo la forma denominada agricultura por contrato; una de las tantas maneras de evadir la formalización del trabajador y, así, evitar pagar los costos que ello implica, incluido la garantía de un salario mínimo.

${ }^{4}$ El litigio por la posesión del sector oriental de Misiones entre la República Argentina y Brasil, fue resuelto por medio del laudo arbitral del presidente de los Estados Unidos, Stephen Cleveland el 5 de
} 
Ramirez. Conflictos territoriales en Misiones: una reconstrucción histórica de la ocupación espontánea de tierras...

Guazú, San Antonio, Chapecó y Chopín. Como respuesta, del lado misionero se fundaron colonias sobre terrenos públicos, se expandió la frontera agraria y se fomentó la inmigración. Cinco meses antes de que se produjera la federalización, el gobierno de la provincia de Corrientes 5 ejecutó la venta de $2.101 .936 \mathrm{Ha} \mathrm{a} \mathrm{"27} \mathrm{personas,} \mathrm{entre} \mathrm{las} \mathrm{que}$ se encontraban personal del Estado y oficiales del Ejército" (Belastegui, 2006). De esta manera, el gobierno nacional logró la administración política y jurídica del Territorio, pero la propiedad de la tierra continuó en manos particulares. Finalmente, el 22 de diciembre de 1881, se creó el Territorio Nacional de Misiones (1881 y 1953), con el propósito de resguardar la frontera del país frente a la situación del litigio fronterizo. En 1882, el nuevo gobernador del Territorio, Rudecindo Roca, puso en marcha una política de promoción de tierras para la colonización según lo establecido por la Ley Avellaneda -de Inmigración y Colonización-, promulgada en octubre de 1876 y la Ley de Venta de Tierras y División de los Territorios Nacionales, $\mathrm{N}^{\circ} 1.265$ del año en curso, propiciando con ello el arribo de inmigrantes europeos a quienes se les garantizó el acceso a la tierra. Estas legislaciones posibilitaron la implementación conjunta de inmigración y colonización, entendida esta última como una ocupación planificada donde el Estado administra los terrenos, ubica los colonos y fomenta las colonias nacionales (Gallero y Krautstofl, 2010).

La inmigración europea, pero también el flujo poblacional fronterizo con Paraguay y Brasil, "contribuyó a la expansión de la frontera agrícola instalando un modelo de distribución de la tierra basado en pequeñas explotaciones" (Kostlin, 2010). Para el caso del sur de Misiones, el arribo de los primeros inmigrantes de origen galizianos a la antigua reducción jesuítica de Apóstoles, en 1897, significó el comienzo de la colonización oficial de tierras públicas. En aquel momento, 14 familias (alrededor de 68 personas) se trasladaron a Misiones como consecuencia de las gestiones del gobernador Juan José Lanusse ante las autoridades de inmigración (Abinzano, 1985). Una vez en estos territorios, el Estado les otorgó un mínimo de " 25 Ha y hasta un máximo legal de $100 \mathrm{Ha}$, de acuerdo con el tamaño del grupo familiar" (Bartolomé, 1975) para ser dedicadas al cultivo de yerba mate, "vía tradicional de constitución de los colonos y de su acceso a la tierra" (Rodríguez, 2015).

En el norte, en cambio, la expansión territorial llevada a cabo a partir de 1920 posibilitó la intervención del capital en la rama forestal bajo la forma de colonización de tierras particulares, impulsada por empresas extranjeras que extraían recursos de los yerbales naturales y deforestaban el monte para hacer uso de la madera (Ramirez, 2017). Esta tarea requirió grandes desembolsos de dinero para la compra de terrenos y, a posteriori, para la inmovilización del capital hasta la venta de la materia prima. Con

febrero de 1895. La disputa comenzó en 1791 entre los comisionados demarcadores de límites de España y de Portugal y continuó en 1881 entre los gobiernos de Argentina y de Brasil. Finalmente, el fallo por la "Questão das Missões", como es conocido por la historiografía brasileña, resultó favorable a los intereses de este país.

5 Entre 1830 y 1865 el territorio misionero estuvo bajo la administración de la provincia de Corrientes y la República del Paraguay. Finalizada la guerra de la Triple Alianza (1870), la totalidad de los territorios de la antigua provincia guaranítica, quedaron bajo la jurisdicción del gobierno correntino. N. del A. 
la expansión del área sembrada hacia finales de la década de 1930, casi la totalidad de las tierras fiscales fueron destinadas para la extensión de los nuevos cultivos. De esta manera, por medio de la compra y administración de terrenos, empresarios particulares estructuraron proyectos sin gerenciar la tierra pública, como establecía la legislación oficial (Gallero y Krautstofl, 2010), por lo que ambas formas de colonización coexistieron aproximadamente hasta 1935.

\section{Provincialización, crisis y agotamiento de la frontera agrícola}

En diciembre de 1953, el presidente Juan Domingo Perón declaró, por medio de la promulgación de la Ley N ${ }^{\circ} 14.294$ del Poder Legislativo Nacional, la provincialización del hasta entonces Territorio Nacional de Misiones. Desde el punto de vista productivo esto significó la incorporación de la población misionera a la dinámica nacional, lo que consolidó un sector encargado de "controlar los principales mecanismos de comercialización e industrialización agrícola" (Schvorer, 2011). Este nuevo escenario favoreció a la foresto-industrial que, hacia 1955, experimentó un crecimiento importante, tanto en lo que respecta a la instalación de empresas madereras como las de producción de pasta celulósica. De esta manera, logró integrar al sector primario con el industrial por medio de la inversión en deforestaciones de grandes extensiones de montes de la zona del Alto Paraná.

Para 1960 la pequeña producción agrícola representaba un 67,5\% del total de explotaciones existentes en la joven provincia. No obstante, las sucesivas crisis de sobreproducción yerbatera y su posterior regulación por parte del Estado Nacional, forzaron la incorporación de pequeños productores al complejo agroindustrial de túng, té y tabaco. Durante las décadas siguientes, la extensión de la actividad forestal, junto a una productividad en alza de la soja y el citrus, provocaron el agotamiento de la frontera agraria y la caída de precios en los cultivos industriales tradicionales. Con ello, sobrevino una nueva crisis en el sector que causó el despoblamiento del sur y centro de la provincia (Slutzky, 2014) y una tendencia a la pauperización, proletarización y la consecuente desaparición de los productores menos capitalizados del norte, hacia 1980. La quita de subsidios al sector foresto-industrial, en 1985, generó la quiebra de las empresas y el posterior abandono de las tierras dedicadas a esta actividad, lo que dejó vacante el espacio que ocuparon productores pauperizados de la antigua colonización y exempleados forestales.

En síntesis, el fenómeno de ocupación de tierras se desarrolló de manera espontánea como resultante del avance de la forestación y la concentración de terrenos en manos de capitales trasnacionales. Esta situación produjo el agotamiento de las áreas destinadas al cultivo $\mathrm{y}$, por consiguiente, una progresiva descapitalización de los sectores agrícolas medios y la pauperización de la pequeña producción que, en general, se incorporó al complejo agroindustrial tabacalero, alternando el cultivo de subsistencia con la producción de tabaco rubio tipo Burley. 
Ramirez. Conflictos territoriales en Misiones: una reconstrucción histórica de la ocupación espontánea de tierras...

\section{Los conflictos por la tierra en el nordeste de la provincia de Misiones}

Primer momento: El abandono de las tierras

"La empresa quiebra y nosotros quedamos, porque había casas para las familias" ${ }$

La superficie abandonada por las compañías madereras, a mediados de 1980, ascendía a $65.000 \mathrm{Ha}$. Luego de la quiebra las propiedades fueron ocupada por ex peones forestales a quienes se le adeudaban jornales, por agricultores provenientes del área meridional de la provincia $\mathrm{y}$, en menor medida, por población proveniente del sur de Brasil. En la actualidad, las familias asentadas en estos terrenos se dedican a la cría animales de corral para autoconsumo y/o cultivar maíz y tabaco rubio tipo Burley en pequeña escala.

Las empresas forestales

Durante el año 1936, en el marco de la colonización de tierras privadas, comenzó a trabajar en el Departamento General Manuel Belgrano la Intercontinental Compañía Maderera S.A. (actualmente Puente Alto S.A), una propiedad del Grupo Dreyfus, Banca Rostchild que abarcaba unas $35.156 \mathrm{Ha}$. Al interior de esta propiedad se pueden distinguir varios asentamientos: Tres Vecinos, Cruce Inter, Inter Vieja, Piraí Miní, Picada 10, Km. 80 y Picada Unión. En 1972 fue adquirida por el Banco Cooperativo San Miguel que instaló en la zona un aserradero y una laminadora. A fines de 1980, al momento de presentar quiebra, la propiedad se encontraba ya hipotecada por el Banco Nación, que en 1999 la puso en remate: 'La 'ex Inter', que se dio a quiebra en esa época, dejó 70-80 familias desamparadas y hablando en números de personas unas 7 u 8 personas por familia. La gente, al año siguiente ya empezaron a pasar hambre, porque la empresa prometía volver y nunca más volvió".

En 1948, se instaló en el Departamento San Pedro, la empresa Colonizadora Misionera S.A. Inmobiliaria, Agrícola e Industrial. Propietaria de unas $29.000 \mathrm{Ha}$, su principal actividad en la zona fue la explotación de monte nativo. Dentro de ella se encuentran los asentamientos: Km. 80 y Km. 90, El Progreso, Juanita, Piraí Guazú, Polvorín, Portón Viejo y Piraí Miní. Hacia 1980, contrajo deudas impositivas que la llevaron a vender parte de su patrimonio a los administradores de Los Cencerros S.A. y Mondorí S.R.L.

Mientras la actividad extractiva estuvo en pleno auge, ambas propiedades fueron pobladas por familias que tenían algún integrante afectado a la explotación del monte. En su mayoría padres e hijos varones, pero también mujeres con descendencia

\footnotetext{
6 Productor ocupante de La Colonizadora, Km. 90, septiembre de 2015. Por tratarse de un proceso que aún no se encuentra cerrado, se decidió resguardar la identidad de las fuentes orales. Siempre que sea posible, sus dichos serán consignados de manera textual, por considerar que en ellos se encuentra parte del conocimiento material y socialmente adquirido durante el proceso de lucha.

7 Productor ocupante de La Colonizadora, Km. 90, septiembre de 2015.
} 
a su cargo, que no contaban con tierras productivas y residían en viviendas que las empresas construían para sus empleados:

Yo trabajé en la propiedad de García ${ }^{8}$, haciendo las cosas de la casa, pero cuando no había nada para hacer, me iba al monte, a desmontar capueras (parte de la selva limpia y lista para sembrar) o juntar los troncos que quedaban. Me pagaban el día, no era mucho, pero llevaba la comida a mis hijos, y yo era sola hasta que me junte con mi marido actual. ${ }^{9}$

Los despedidos de la actividad forestal

La década de 1980 en Argentina estuvo signada por una fuerte crisis social y económica, heredada de la última dictadura militar(1976-1983). Pese a la implementación de nuevas políticas económicas, el gobierno democrático de Raúl Alfonsín (19831989) no logró atemperar la crisis monetaria. En estas circunstancias, hacia 1985, se estancaron los créditos fiscales destinados a la forestación, lo que precipitó la caída de la rentabilidad del sector y generó la quiebra de la Colonizadora y la Intercontinental, que abandonaron los terrenos emplazados sobre los departamentos de Guaraní, General Belgrano y San Pedro; localidad donde se encuentra el actual Municipio de Pozo Azul ${ }^{10}$, epicentro de los conflictos por la tierra en el norte de la provincia de Misiones. Desde ese momento, los despedidos de la actividad forestal y sus familias se asentaron en los terrenos que habían sido dedicados a la explotación maderera -en algunos casos con permiso de sus propietarios-, donde actualmente existe una tercera generación que habita el lugar y reclama por las tierras:

"La realidad es clara: sesenta por ciento son familias locales de acá. Hijos de los troncos que vinieron a trabajar con las empresas: hijos, nietos, como mi caso. Nosotros somos 5 hermanos, entonces, en la época era una familia, hoy somos seis familias". ${ }^{11}$

Del testimonio puede observarse, por un lado, que no se respetan las leyes de prescripciones veinteñales, mediante el cual un/a poseedor/a puede a adquirir la propiedad por el paso del tiempo mediante el juicio de prescripción y, por otro, la cantidad de tiempo que pasó sin que el Estado haya desarrollado una política de titularización de tierras.

\footnotetext{
8 La entrevistada hace referencia al empresario forestal Francisco Serafín García, quien fuera gerente y luego presidente de la empresa Colonizadora Misionera S.A. Inmobiliaria Agrícola e Industrial, desde febrero de 2009 hasta su fallecimiento en febrero de 2011. Actualmente, ese lugar lo ocupa su hijo Francisco Luis García.

9 Productora ocupante de La Colonizadora, Km. 80, febrero de 2019. La aclaración entre paréntesis es del autor.

${ }^{10} \mathrm{Al}$ momento de comenzar esta investigación (2013) Pozo Azul aún era un paraje del Departamento San Pedro. El 12 de octubre de 2017, fue declarado como el "Municipio 76" de la provincia de Misiones.

${ }^{11}$ Productor ocupante de la Colonizadora Km. 90, septiembre de 2015.
} 
Ramirez. Conflictos territoriales en Misiones: una reconstrucción histórica de la ocupación espontánea de tierras...

En este punto es importante caracterizar brevemente al sujeto señalado como poseedor/a, puesto que es la figura legal que reviste la mayor parte de la población ocupante. En rigor, son poseedores/as todo aquellos que viven, trabajan o utilizan la tierra como su propietario/a:

También suele encontrarse en la bibliografía como con ánimo de dueño, a la persona que tiene la posesión de la tierra si tiene ánimo de dueño y realiza actos posesorios (estar viviendo en el lugar, trabajando y haciendo mejoras como corrales, cercos, represa, huerta, pozo, cementerio, picadas, rancho, galpón, potreros, piruas o trojas, senderos, deslindes etc. y el pago de impuestos). (Bidaseca, 2012).

Procesos más recientes muestran otra forma de ocupación vinculada a la producción tabacalera; familias provenientes del sur y centro de la provincia, en búsqueda de tierras para el cultivo ocuparon terrenos cuyos propietarios no se encontraban asentados en la zona:

Polvorín, El Km. 90 y Santa Rosa, empezó a poblarse de tabacaleros en 2004 o 2005 más o menos. El espacio que ellos estaban ocupando era tierra de García, el dueño [...] Siempre respetaron eso. Agarraron lo que era monte nativo. En cambio, la otra gente, sí llegaron y se metieron de 'prepo' en esa parte ahí donde después los desalojaron. Ellos no eran plantadores de tabaco, eran más peones que otra cosa, no tenían plantaciones fijas. $^{12}$

En todos los casos la ocupación de terrenos privados se produjo cuando las familias se encontraban en una situación que "ponía en riesgo su propia subsistencia" (Kostlin, 2010, p.11). Esto explica, en parte, la espontaneidad y la falta de planificación previa con las que fueron desarrolladas las ocupaciones.

\section{Segundo momento: Desarrollo de la ocupación espontánea}

Quienes toman terrenos que no les pertenecen atentan contra el trabajo estable, alientan los vicios de la inmoralidad tolerada, privan a los municipios de cobrar sus tasas, disminuyen los ingresos provinciales provenientes del impuesto inmobiliario y generan un comercio paralelo e ilegal de maderas, que obviamente tampoco tributa al fisco. ${ }^{13}$

La gente entró y empezó a usar más o menos según la necesidad que tenía. Si tenía una vaca y necesitaba 2 o 3 hectáreas, se ocupaba $[\ldots]$ así fue la ocupación. ${ }^{14}$

\footnotetext{
12 Productor ocupante de la Intercontinental, Tres Vecinos, 2015.

${ }^{13}$ Edgard Castro, apoderado de la firma Colonizadora Misionera. Diario La Nación, 29/09/2002.

${ }^{14}$ Productor ocupante de la Colonizadora, Tres Vecinos, 2015.
} 
Con la implementación de políticas estatales (en el sur y centro de la provincia), o a partir de emprendimientos privados (en el norte), el proceso de ocupación del espacio misionero se realizó a partir de la expansión de explotaciones agrarias. De esta manera, el negocio forestal que impulsó la colonización privada en el área bajo estudio también garantizó la fuerza de trabajo necesaria para la actividad extractivista.

La ocupación espontánea y la conformación de un mercado informal de tierras

La espontaneidad a la hora de ocupar los terrenos abandonado por la actividad forestal se presentó como un rasgo característico de esta nueva etapa de colonización del territorio. En consecuencia, el desconocimiento de las dimensiones reales de las parcelas ocupadas aparecía como un elemento común en los relatos:

"Cuando vinieron a hacer la mensura encontraron familias que decían tener $30 \mathrm{Ha}$. con $17 \mathrm{Ha}$, porque no se sabía ni lo que se tenía. Usabas así, sin saber lo que usabas" ${ }^{\prime 5}$.

Las situaciones relacionadas a la tenencia de la tierra se dieron bajo múltiples formas, desde una familia que consideraba terreno fiscal a una parcela de tierra por el ausentismo de sus propietarios, hasta empresarios forestales u otros ocupantes que ofertaban como propios terrenos privados o con deudas con el fisco. Esto originó un mercado informal de tierras en la zona, donde fueron implementadas por lo menos dos formas de adquisición de terrenos: a) el brique: un ejercicio de intercambio sin intervención del dinero como mercancía equivalente, ejecutado sobre la base del binomio necesidad/beneficio de cada parte al momento de realizar el negocio y b) la compra de mejoras: adquisición de parcelas por las que las familias pagaban a un vendedor que las ofertaba como propias.

En varias oportunidades durante el relevamiento en campo, los entrevistados señalaron que este último método fue el más utilizado para ocupar y valorizar los terrenos de la zona. Sin embargo, para evitar caer en la simplificación a la hora de exponer las estrategias de reproducción social llevada adelante por esta población, conviene considerar estos dichos en relación a la noción de "legitimidad" que presentan, pues es común que supongan "más legítima" la adquisición de mejoras que la ocupación directa, por lo que su respuesta puede encontrarse condicionada por esta concepción.

El movimiento piquetero y la lucha por la tierra en el norte de Misiones

El congelamiento de salarios y la reducción del gasto público, sumados al proceso hiperinflacionario de finales de la década del ochenta, obligaron al presidente Alfonsín a pactar una salida anticipada del gobierno. En su lugar, el 8 de julio de 1989, asumió Carlos Saúl Menem, quien ocuparía este lugar durante diez años. A meses de inaugurar su primer mandato (1989-1995), el Congreso de la Nación decretó la Ley de Convertibilidad -prolongada hasta el año 2002- que puso a la moneda nacional bajo el resguardo de las

${ }^{15}$ Productor ocupante de la Colonizadora, Tres Vecinos, 2015. 
Ramirez. Conflictos territoriales en Misiones: una reconstrucción histórica de la ocupación espontánea de tierras...

reservas del Banco Central de la Nación, lo que generó una relación de paridad cambiaria en el que un peso argentino equivalía a un dólar estadounidense. Posteriormente, en marzo de 1991, se aprobó la Ley de Reforma del Estado que autorizó la privatización de la mayoría de las empresas estatales. Estas medidas lograron una estabilidad económica temporal, sobre la base del endeudamiento externo y el ingreso de capitales extranjeros, lo que alentó un segundo mandato presidencial de Menem (1995-1999).

Caracterizado por una fuerte recesión económica y altos índices de desocupación, durante este último período comenzaron a proliferar en todo el país un conjunto de organizaciones que nucleaban a trabajadores desocupados, un fenómeno de masas que se convertiría en un factor determinante en la política argentina: el movimiento piquetero. Si bien su primera aparición data de finales de 1993 (durante el primer mandato de Menem), cuando empleados estatales de la ciudad de Santiago del Estero incendiaron la sede de gobierno en reclamo de sueldos adeudados, las imágenes que recorrieron el país exponiendo el llamado método piquetero, se desarrollaron entre 1995 y 1997 en las ciudades de Cutral-Có y Plaza Huicul en Neuquén y Gral. Mosconi y Tartagal en Salta, ubicadas en regiones cuya economía dependía esencialmente de las cuencas gasíferas y petrolíferas que habían sido privatizadas por el Estado Nacional.

Entre 1993 y 1997, el capital extranjero destinó alrededor de 1.000 millones de dólares para reactivar la industria forestal en Misiones, mientras que entre 1997 y 2002 la empresa Alto Paraná S.A. invirtió alrededor de 288 millones de dólares en el agronegocio. Esta inyección masiva de capitales restableció el valor productivo de las tierras abandonadas y abrió un período de conflictos entre las empresas, que buscaron recuperar sus terrenos, y la población ocupante. Esta última, ante las constantes amenazas de desalojo, comenzó a establecer vínculos con diferentes ONG's que contaban con "los conocimientos necesarios para formular demandas y darle una posible solución al conflicto" (Otero, 2008).

Lo novedoso del asunto es que, en este recóndito lugar del país, un centenar de familias rurales con el objetivo de defender la tierra como medio de vida asumieron el desafío de fraguar sus propias organizaciones y desarrollar una herramienta política que caracterizaría su accionar: el piquete, para la lucha, y la asamblea para la toma de decisiones.

\section{El Plan de Arraigo y Colonización}

Una experiencia linda porque uno fue conociendo como es la cosa, porque estando en la chacra no conoces nada. Ahí uno aprende sus derechos. Con eso ahí conseguimos el Plan de Arraigo ${ }^{16}$.

Gracias a la incesante lucha que llevaron adelante las familias ocupantes, en el año 2000, consiguieron reducir de 16 años a 60 meses el período mínimo de ocupación establecido por la Ley Provincial № 36 (antes Ley $\mathrm{N}^{\circ} 3.141$ ), que además limitaba la participación del

\footnotetext{
${ }^{16}$ Productora ocupante de la Colonizadora, Km. 80, 2019.
} 
Estado provincial en el proceso de regularización y dominio de la tierra. Durante los años 2001 y 2004 las medidas de fuerza continuaron con un nivel de convocatoria cada vez mayor. En consecuencia, los ocupantes consiguieron los primeros logros parciales: a) titularización de pequeñas porciones de tierras, b) la relocalización de familias no contempladas en la Ley y c) la entrega de permisos de ocupación y otorgamientos de subsidios para mensuras. Sin embargo, las partes no llegaron a un acuerdo en relación al costo y la cantidad de superficie que las empresas venderían al Estado.

El 18 de noviembre de $2004^{17}$, ante un estado de creciente agitación, en la Cámara de Representantes de la ciudad de Posadas se promulgó la versión final de la Ley No 4.093 o Plan de Arraigo y Colonización, donde además de la compra de $75.000 \mathrm{Ha}$ declaradas de utilidad pública pertenecientes a las empresas Intercontinental Compañía Maderera S.A, CATO SRL (Agroforestal) y Colonizadora Misionera S. A., el Estado asumió el compromiso de otorgar créditos para vivienda, producción y capacitación técnica a los ocupantes con el objetivo de posibilitarles el acceso a la tierra. A pesar de la promulgación de la Ley, el Estado y las empresas manifestaban seguir sin llegar a un acuerdo en relación al costo de venta de los terrenos.

En diciembre de 2006, luego de un acampe realizado por productores de Pozo Azul frente a la Casa de Gobierno en reclamo de la ejecución del Plan, se prorrogó su aplicación por un año. Esto despertó el descontento entre los ocupantes que volvieron a sus chacras y comenzaron un nuevo proceso de organización. Durante el 2007, los conflictos recrudecieron. En enero de ese año, 41 familias -un total de 180 personas-, oriundas de la localidad de El Soberbio, fueron intimados a desalojar sus viviendas, llegando a un acuerdo solo luego de la intervención del Juzgado de Paz de la zona. Por otra parte, en el mes de abril, alrededor de un centenar de ocupantes nucleados en la CCT-A del paraje Mondorí y el Progreso, ubicados a $8 \mathrm{Km}$. de Pozo Azul, volvieron a cortar la ruta por haber sido excluidos de los límites propuestos por el Plan de Arraigo y Colonización. Durante, en el mes de septiembre, se produjeron nuevos cortes de ruta en reclamo por la deforestación del monte nativo en Cencerro S.A, propiedad de Jorge Ottonelo, en la que además funcionaba un aserradero encargado de los cortes y el refinamiento de la madera extraída. En esas tierras se encontraban asentadas 60 familias que solicitaban la inclusión de sus predios a la orden de compra del Plan.

Recién durante el año 2008, y ante la presión que ejercían las organizaciones vinculadas a la lucha por la tierra, el Estado provincial comenzó los trabajos de mensuras en algunos lotes que ya habían sido adquiridos y se entregaron permisos de residencia en la localidad de San Vicente. Por su parte, en noviembre de 2010, tuvo lugar una reunión con más de 100 referentes de distintas organizaciones de ocupantes con la Subsecretaria de Tierras de la provincia. Al pedido de ampliación del territorio afectado por el Plan de Arraigo y Colonización se le sumó el reclamo por falta de energía eléctrica en la

\footnotetext{
${ }^{17}$ En este año, la Facultad de Humanidades y Ciencias Sociales de la UNaM, realizó el primer el Censo de Ocupantes de Tierras Privadas -único relevamiento cuantitativo existente acerca de la población bajo estudio-, sobre éste se desarrollaron todos los planeamientos necesarios para estimar la cantidad de unidades domésticas, lotes y habitantes, al igual que un trabajo de determinación de superficies de las tierras ocupadas.
} 
Ramirez. Conflictos territoriales en Misiones: una reconstrucción histórica de la ocupación espontánea de tierras...

zona. Los productores insistieron en la necesidad de una constancia de ocupación que les permitiera acceder a programas productivos y servicios como la conexión eléctrica, ya que la falta de título de propiedad era el obstáculo principal para la obtención del servicio. En esa oportunidad, el entonces Subsecretario de Tierras, Jaime Ledesma, manifestó que en el marco de las gestiones que estaban realizando enviarían informes sobre las familias ocupantes a los Ministerios del Agro y Ecología para agilizar el ingreso de éstas a los planes correspondientes, asumiendo el compromiso de realizar consultas ante el presidente de Electricidad de Misiones S.A. (EMSA), para instalar los tendidos eléctricos necesarios.

En marzo de 2011, el mismo Subsecretario de Tierras, volvió a reunirse con más de 130 productores de San Pedro y zonas aledañas por el mismo inconveniente. Casi un año más tarde, el 7 de febrero de 2012, el diario El Territorio titulaba: "Colonos de Pozo Azul se movilizarán en reclamo de electrificación rural", lo que evidenciaba que la problemática persistía a pesar de las promesas del Estado. La regularización de estos terrenos junto con la entrega de los títulos llegó recién en marzo de 2012, momento en que se oficializó la cifra de $22.000 \mathrm{Ha}$. de terrenos fiscales rurales dispuestos a ser entregados al Estado. Esta cifra representa poco menos de un tercio de las $75.000 \mathrm{Ha}$ que habían sido declaradas de utilidad pública por la Ley de Arraigo y Colonización.

Además de la significativa diferencia en cuanto a la superficie a ser adquirida, es posible que el acuerdo entre el Estado y las empresas forestales por el precio de compra de las mismas haya resultado más conveniente a los empresarios que a los productores. Para los primeros, tener tierras sin ser explotadas no significa un negocio rentable, mientras que para las familias ocupantes el compromiso de pago por sus tierras les generó una deuda que, en muchos casos, no pudieron asumir:

Después que salió la mensura acá, muchas gentes se fueron, no pudieron pagar. Vos decís 'diez años no es mucho', pero hay que tener cuando llega la boleta. Ellos se fueron, pero hicieron plata también, vendieron tierras chiquitas por $\$ 150.000$ o cambiaron por autos. No sé si para ellos es plata o tenían miedo o no podían pagar. Capaz que no podían pagar ${ }^{18}$.

Tercer momento: Represión e intento de desarticulación de las experiencias organizativas Los desalojos

El conflicto frena inversiones y, en consecuencia, el crecimiento socio económico de la zona. He llevado inversores para poner una industria forestal y para otras iniciativas, pero llegan allá, ven la ocupación ilegal y no quieren invertir. ${ }^{19}$

Hace 5 años que vivo acá. Tengo mi plantación de yerba y tengo un galpón con 8 mil kilos de tabaco, chanchos, gallinas y dos yuntas de buey y ahora me quedé sin nada. Yo sé que

\footnotetext{
${ }_{18}$ Productor ocupante de la Intercontinental, Cruce Inter, febrero 2019.

${ }^{19}$ Francisco Luis García. Presidente de Colonizadora Misionera S. A. Diario El Territorio 13/06/2014.
} 
cometí un error, pero estoy desesperado. ${ }^{20}$

Nos juntamos con estas familias varias veces y les aclaramos que ellos no cumplían con los requisitos mínimos para entrar en la negociación que lleva adelante la provincia con los dueños de esas tierras y se les avisó de la causa varias veces, pero no hicieron caso. ${ }^{21}$

En febrero de 2013, nuevamente, familias de los parajes Mondorí y Puente Alto, emplazados en el Departamento de San Pedro, recibieron una orden de desalojo por parte de la Secretaría Uno del Juzgado de Instrucción N. ${ }^{\circ} 3$ de San Vicente:

"Hoy vuelven los mismos zánganos que en esas épocas usaron a la gente como esclavos y quieren desalojar para adueñarse de cosas que ya no es de ellos [...] cuando no había más madera nativa abandonaron a la gente y ahí viene la ocupación, porque la gente no tiene para comer, no tiene de donde sacar, hay que trabajar la tierra, hay que producir, hay que comer de ahí, entonces ahí se fueron armando las chacras"22.

Los lotes sujetos a desalojo eran propiedad de la empresa Colonizadora Misionera S.A. y la superficie de los mismos sumaba un total de 28.882 Ha. Allí, desde 2011, 26 familias se encontraban ocupando $8.882 \mathrm{Ha}$ que no estaban en el orden de compra por parte del Estado. En esa oportunidad el Subsecretario de Tierras de la provincia detalló que la empresa tenía 30.000 Ha. en la zona de Pozo Azul, de las cuales, por medio de la aplicación de la Ley de Colonización y Arraigo, el gobierno había expropiado 19.000 $\mathrm{Ha}$, pero que el conflicto se desató porque los ocupantes reclamaban $800 \mathrm{Ha}$ de las restantes 11.000 Ha que no están sujetas al proceso de compra ${ }^{23}$.

El desalojo se efectúo el 8 de abril de 2013, en medio de una mesa de diálogo entre los representantes de los ocupantes y el Estado, en donde los productores llevaron el reclamo de regularización de las tierras que habitaban hacía más de 10 años. Luego de los desalojos los ocupantes no recibieron respuestas del Estado, por lo que nuevamente se volcaron a fortalecer la lucha en la ruta:

"Del desalojo nadie se quiso hacer cargo ¡No vino ningún funcionario! pero en las mesas de diálogo habían participado el director de tierras, Felipe Domínguez del MAM, el Intendente de San Pedro y el Ministro de Derechos Humanos, que salió diciendo que desconocía el tema. Entonces no quedó otra ¡volvimos a la ruta!"24.

\footnotetext{
${ }^{20}$ Productor ocupante. Diario El Territorio, 9/04/2013.

${ }^{21}$ Jaime Ledesma, ex Subsecretario de Tierras de la provincia.

${ }^{22}$ Productor ocupante de la Colonizadora, Km. 90, septiembre de 2015.

${ }^{23}$ Diario El Territorio, 28/02/ 2013.

${ }^{24}$ Productor ocupante de la Colonizadora, Km. 90, noviembre de 2017.
} 
Ramirez. Conflictos territoriales en Misiones: una reconstrucción histórica de la ocupación espontánea de tierras...

Producto de los cortes, un mes más tarde, se firmó un acta de acuerdo donde el Estado provincial se comprometía a adquirir dos lotes de 1.000 Ha para las familias afectadas. Asimismo, se acordó que no se efectuarían más desalojos, cesaría el hostigamiento judicial y se procedería al inmediato desprocesamiento de todos los detenidos. Sin embargo, entre los meses de abril y agosto la ruta continuó cortada por largas horas al día, debido al incumplimiento por parte del Estado del compromiso asumido. En julio de 2013 se establecieron nuevos convenios de cooperación para la adquisición de $378 \mathrm{Ha}$ de tierras en la zona de Puerto Argentino, mientras que en septiembre de ese mismo año se llegó a un arreglo para regularizar la locación de 70 familias que ocuparon alrededor de $1.400 \mathrm{Ha}$ en Colonia Victoria, ambas propiedades de la firma Riceri S.A., también ubicadas en el Municipio de San Pedro.

\section{Reflexiones finales}

La tarea de historizar la ocupación de Misiones, desde su colonización hasta el agotamiento de la frontera agrícola, permite, por un lado, observar cuales fueron los factores que desencadenaron los conflictos por la tierra y, por otro, el lugar que ocupó el Estado en dicho proceso. De esta manera, se evidencia que la incorporación de capitales transnacionales para el desarrollo forestal, a comienzos del siglo XX, impulsó la ocupación del nordeste de la provincia. Asimismo, pudimos ver como el capital forestal, con el objetivo de garantizar las mejores condiciones para su expansión, acumuló medios de producción -en este caso tierra- y reclutó la fuerza de trabajo necesaria para la realización de las tareas que demandaba dicha actividad. A esta situación se le sumaron las sucesivas crisis de la yerba mate y la extensión de los complejos agroindustriales, lo que finalmente puso coto a las aspiraciones de capas enteras de población rural dedicadas a los cultivos tradicionales, obligándolos a procurar mejores condiciones para su reproducción.

Para mediados de 1980 la economía nacional se encontró en medio de una crisis que ocasionó un severo estancamiento en la producción forestal. En este contexto las empresas abandonaron de sus propiedades en el nordeste de la provincia de Misiones. Bajo estas circunstancias, y sobre estas fincas, comenzó a gestarse la ocupación de terrenos privados, por lo que su desarrollo expresa cabalmente el empobrecimiento de pequeños y medianos productores que de forma progresiva fueron perdiendo su capacidad de reproducción; ya sea por descapitalización -en el caso de los sectores agrícolas medios- o debido a un proceso sostenido de pauperización, como ocurrió con la pequeña producción fundiaria.

En cuanto al comportamiento del Estado con relación a la actividad forestal, desde la colonización de tierras privadas (1920), su accionar tendió a favorecer el desarrollo foresto-industrial, en ese momento con la entrega de terrenos que luego serían dedicados a la explotación maderera. Por otro lado, a lo largo del siglo XX, a través de subsidios a esta actividad, con el objetivo de garantizar un mayor nivel de productividad en la rama. Sin embargo, el punto de inflexión para el caso que nos ocupa, se dio con el millonario desembolso de capitales extranjero que entre 1993 y 
1997 reactivó a la industria forestal, por lo que los empresarios comenzaron a reclamar la propiedad de los terrenos que habían abandonado durante la década anterior. Frente a esta situación, y ante la organización de la población ocupante en defensa de las tierras, el Estado volvió a intervenir en el conflicto como mediador, esta vez partir de la sanción de la Ley 4.093 o Plan de Arraigo y Colonización que vino a salvaguardar los intereses del capital forestal.

Sin dejar de reconocer que el proceso de lucha desarrollado por los ocupantes fue la piedra angular sobre la que se montaron todas las reivindicaciones conseguidas, principalmente la sanción de la Ley de Arraigo, no se debe minimizar la intervención del aparato estatal en el desenlace del conflicto, por cuanto su naturaleza de Estado capitalista lo posicionó por encima de los intereses de las partes involucradas con el objetivo de atemperar las situaciones de conflicto. En este sentido, si bien Ley de Arraigo atendió la demanda central por la que lucharon los ocupantes, la propiedad de la tierra también tuvo la característica de haber sido el instrumento legal con el cual se garantizó el orden y, con ello, la protección de los intereses del capital forestal frente a la organización de la población ocupante.

La sanción de Ley de Arraigo favoreció a los empresarios, en la medida en que estos recibieron una importante cifra de dinero por la venta de lotes declarados de utilidad pública por dicha Ley. Cabe mencionar que se trata de solamente la mitad de la superficie dispuesta por la Ley que, además, continuó siendo explotada durante los diez años que tardaron en instrumentar su implementación. Se infiere, entonces, que se trata de tierra poco fértil y, en consecuencia, sin demasiada rentabilidad para las compañías forestales. Lo "equitativo", en términos de distribución de recursos, hubiera sido el paso de una propiedad individual a una colectiva. No obstante, lo que sucedió fue la profundización de un proceso de mercantilización de la tierra que vino desarrollándose desde principios de siglo XX, cuando el Estado vendió enormes extensiones de terrenos a empresas forestales, las mismas que en 2015 se las volvieron a vender por un valor mayor. Finalmente, el Estado se las vende a las familias ocupantes en el marco del proceso de regularización de terrenos.

En líneas generales, los conflictos por la tierra son la resultante de las contradicciones principales del modo de producción específicamente capitalista que por más de medio siglo propició el avance de la forestoindustria, en desmedro de las condiciones de vida y de trabajo de miles de productores rurales y sus familias. En este contexto, la única posibilidad para superar esta situación se encuentra sujeta a la supresión de las relaciones sociales que le otorgan sentido. Sin embargo, por el grado de complejidad que asumió, la cantidad de población involucrada y el nivel de organización que alcanzó la lucha por la tierra impulsada por los ocupantes, se considera que esta representa el punto más álgido en el desarrollo de la lucha de clase de los últimos treinta años en la provincia de Misiones.

Esta conclusión se desprende de la perspectiva que se decidió implementar en este análisis, con la cual se logró realizar una descripción de los aspectos particulares de la problemática estudiada sobre la base de la observación de la totalidad del proceso. De 
Ramirez. Conflictos territoriales en Misiones: una reconstrucción histórica de la ocupación espontánea de tierras...

esta manera se constata, por un lado, la disposición a la lucha de la población ocupante que, motivados por la necesidad de conservar sus medios de vida, defendieron hasta las últimas consecuencias los intereses del colectivo. Por otro lado, la voluntad la de los empresarios forestales, quienes -como cualquier otro capitalista individual- encontraron en el sistema social los argumentos económicos y políticos para someter a las peores condiciones de explotación, y de vida, a capas enteras de clase obrera rural. En este caso, con el fin de garantizar su existencia a costa de una creciente concentración y explotación de la tierra.

Finalmente, se considera que el aporte más significativo de este artículo radica en la intención de recuperar las categorías del materialismo histórico para el análisis de los conflictos territoriales en la provincia de Misiones. Ello se debe a que la sistematización de un planteo de este tipo puede favorecer la apertura de una nueva perspectiva, que tenga como propósito el desarrollo del conocimiento científico como forma de organizar la acción política.

\section{Referencias bibliográficas}

Abínzano, R. (1985) Procesos de Integración en una sociedad multiétnica: la provincia argentina de Misiones. Universidad de Sevilla: Tesis doctoral Departamento de Antropología y Etnología de América, Inédita.

Baranger, D. (2008) "La construcción del campesinado en Misiones: de las Ligas Agrarias a los "sin tierra"”. En G. Schiavoni (Comp.). Campesinos y agricultores familiares: la cuestión agraria en Misiones a fines del siglo XX. Buenos Aires: Editorial Ciccus, pp. 33-70.

Bartolomé, L. (2007) Los colonos de Apóstoles. Estrategias adaptativas y etnicidad en una colonia eslava en Misiones. Posadas: Editorial Universitaria de Misiones.

Belastegui, H. (2006) Los colonos de Misiones. Posadas: Editorial Universitaria de Misiones.

Bidaseca, K. (2003) Los sin tierra de Misiones. Disputas políticas y culturales en torno a las ocupaciones de tierras y las migraciones de brasileña/os en un pueblo argentino de frontera. Programa de Becas CLACSO-Asdi de promoción de la investigación social. Buenos Aires.

Caligaris, G. (2012) "Clases sociales, lucha de clases y Estado en el desarrollo de la crítica de la economía política". En Caligaris, G.; Fitzsimons, A. (Comp.). Relaciones económicas y políticas. Aportes para el estudio de su unidad con base en la obra de Karl Marx. Buenos Aires: UBA-FCE, pp. 72-91.

Caligaris, G. (2017) Acumulación de capital y sujetos sociales en la producción agraria pampeana (1996-2013). Buenos Aires: Facultad de Ciencias Sociales de la UBA-Teseo.

De Angelis, M. (2012) "Marx y la acumulación primitiva. El carácter continuo de los" cercamientos" capitalistas". Revista Theomai, 26. 
Engels, F. (1992) El origen de la familia, la propiedad privada y el estado. Buenos Aires: Editorial Planeta.

Engels, F. (1986) Ludwing Feuerbach y el fin de la filosofía clásica alemana. Obras escogidas vol.II. URSS: Editorial Progreso.

Galafassi, G. (2014) Apuntes de acumulación: Capital, Estado, procesos socio-históricos de (re) producción y conflictividad social. Buenos Aires: Extramuros Ediciones.

Gallero, C.; Krautstofl, E. (2010) "Proceso de poblamiento y migraciones en la Provincia de Misiones, Argentina:(1881-1970)”. Revista Avá, 16, 2010. (245-264).

Graciosi, M.; Román, M.; Pratesi, A. R. (2018) “Observatorio de conflictos sociales del Nordeste Argentino. Abordaje conceptual y metodológico". De Prácticas y Discursos, Vol. 7, № 9, pp. 117-140.

Iñigo Carrera, J. (2000) “Crisis y perspectivas del capitalismo argentino". Realidad Económica. Buenos Aires, No 171, pp. 52-75.

Iñigo Carrera, J. (2013) El capital: razón histórica, sujeto revolucionario y conciencia. Buenos Aires: Imago Mundi, 2013.

Iñigo Carrera, J. (2015) "Del capital como sujeto de la vida social enajenada a la clase obrera como sujeto revolucionario". En: Coloquio internacional sujeto capitalsujeto revolucionario. Epistemología y análisis crítico del sistema capitalista y sus contradicciones. México: Universidad Autónoma Metropolitana-Xochimilco.

Kosik, K. (1967) Dialéctica de lo concreto. México: Grijalbo.

Kostlin, L. (2010) "Ocupaciones de tierras privadas y conflicto en el nordeste: La conformación de un ciclo inicial de lucha por la tierra en Misiones”. En M. Manzanal y F. Villareal (Comp.). El desarrollo y sus lógicas en disputa. Buenos Aires: Ediciones CICCUS, pp.47-70.

Otero, N. (2008) "De la chacra al corte. Los dirigentes de Unión Campesina y la lucha por la tierra en el nordeste de Misiones". En G. Schiavoni (Comp.). Campesinos y agricultores familiares: la cuestión agraria en Misiones a fines del siglo XX. Buenos Aires: Ediciones CICCUS, pp. 71-98.

Marx, K. (2004) Introducción general a la crítica de la economía política (1857). Buenos Aires: Siglo XXI editores.

Marx, K. (2009) El Capital, Argentina: Siglo XXI editores, T I.

Marx, K. (2009 b) El Capital, Argentina: Siglo XXI editores, T. I. Vol. II.

Marx, K. (2009 c) El Capital. Argentina: Siglo XXI editores, T. III, Vol. VIII.

Ramírez, D. (2017) "Un abordaje histórico de la actividad forestal en Misiones: del frente extractivo al agronegocio forestal". Revista Folia Histórica del Nordeste, 30 , pp. 29-51.

Ramirez, S. (2015) “Trabajo que se hace humo. Sobre la condición social de los ocupantes tabacaleros en el nordeste de Misiones". En: XI Jornadas de Sociología. Buenos Aires: Facultad de Ciencias Sociales.

Rodríguez, L. (2015) "Estado y producción: la actividad yerbatera en el territorio nacional de Misiones (1926-1953)". Revista Folia Histórica del Nordeste, 23, pp. 43-64. 
Schvörer, E. (2001). "Materiales para el estudio del campo de la tierra en Misiones: la ocupación de tierras privadas". Revista Estudios Regionales, 20, pp. 79-81.

Slutzky, D. (2014) Estructura social agraria y agroindustria del Nordeste de la Argentina. Desde la incorporación a la economía nacional al actual subdesarrollo concentrador y excluyente. Posadas: Editorial Universitaria de Misiones.

\section{Fuentes}

Diario Misiones On Line, Posadas-Misiones - 18/10/2014.

Diario El Territorio, Posadas-Misiones - 10/04/ 2007.

Diario El Territorio, Posadas-Misiones - 13/06/2014.

Diario El Territorio, Posadas-Misiones - 9/04/2013.

Diario El Territorio, Posadas-Misiones - 28/02/2013.

Diario Página 12, Buenos Aires - 20/12/2007.

Diario Página 12, Buenos Aires - 03/02/2003.

Diario La Nación, Buenos Aires - 29/09/2002. 